Article

\title{
Highly Efficient Acetalization and Ketalization Catalyzed by Cobaloxime under Solvent-Free Condition
}

\author{
Yang Zong ${ }^{1,2}$, Liting Yang ${ }^{1}$, Shanyu Tang ${ }^{1}$, Longjia Li ${ }^{1}$, Wanjie Wang ${ }^{2}$, Bingxin Yuan ${ }^{1, *}$ \\ and Guanyu Yang ${ }^{1}$ \\ 1 College of Chemistry and Molecular Engineering, Zhengzhou University, Zhengzhou 450001, China; \\ zongyang155@163.com (Y.Z.); hxxyangliting@163.com (L.Y.); tangshanyu81@163.com (S.T.); \\ lilongjia729@163.com (L.L.); yangguanyu@zzu.edu.cn (G.Y.) \\ 2 School of Material Science and Engineering, Zhengzhou University, Zhengzhou 450001, China; \\ wwj@zzu.edu.cn \\ * Correspondence: bxyuan@zzu.edu.cn
}

Received: 30 November 2017; Accepted: 22 January 2018; Published: 26 January 2018

\begin{abstract}
An efficient catalytic system was developed for the acetalization and ketalization of carbonyl compounds with polyhydric alcohols under mild solvent-free conditions. In the presence of $0.1 \mathrm{~mol} \%$ $\mathrm{CoCl}_{2}$ and $0.2 \mathrm{~mol} \%$ dimethylglyoxime at $70{ }^{\circ} \mathrm{C}$ under $5 \mathrm{KPa}$ pressure for $1 \mathrm{~h}, 95.3 \%$ conversion of cyclohexanone and $100 \%$ selectivity of the corresponding cyclic ketal could be obtained, where TOF reached as high as $953 \mathrm{~h}^{-1}$. It is proposed that the in situ generated planartetracoordinate cobaloxime played the key role in the catalytic cycle and was responsible for the excellent catalytic performance.
\end{abstract}

Keywords: acetalization; ketalization; dimethylglyoxime; cobalt; cobaloxime; polyhydric alcohol

\section{Introduction}

The protection of carbonyl groups plays an important role in multi-step organic synthesis ofcompounds with multiple functional groups. Cyclic acetals and ketals are the most well-established and frequently used protective strategies for the carbonyl groups [1]. In addition, many acetals and ketals have wide applications in industrial manufacturing, such as cosmetics, food and fragrances, etc. [2]. The most general method for the synthesis of acetals or ketals is the reaction of carbonyl compounds with an alcohol or diol. Traditionally, acidic catalysts like protic acid $[1,3,4]$, Lewis acid [5-9], and heteropoly acids [10] were used to synthesize acetals or ketals, and the removal of by-product water was essential. However, those methods suffered from several drawbacks, such as corrosion, tedious work-up, environmental pollution and non-recoverability of catalysts. To solve those problems, a variety of solid acidic catalysts, which were prepared by immobilization of acidic catalysts on various inorganic or organic supporters, have been investigated [11-20]. Furthermore, many acid or Lewis acid-functionalized ionic liquids were used for acetalization or ketalization [21-24]. However, such catalysts required complex synthetic routes and long technological processing. As complementary methods to the acid-catalyzed acetalization and ketalization, some metal-free catalysts, such as N-bromobutanimide (NBS) [25] and complexes of carbon tetrabromide and sodium triphenylphosphine- $m$-sulfonate [26] have been developed, which allow the survival of acid-sensitive groups on substrates. Recently, transitional metal complexes have been used to catalyze the acetalization and ketalization of carbonyl compounds and alcohols [27-30]. Despite the great advances in this realm, these methodologies are susceptible to expensive metal catalysts, high catalyst loading, uncommon reagents, and long reaction time. Catalytic systems with non-noble metals and simple ligands are still limited [31-34]. 
Previously, we reported the catalytic aerobic oxidation of alcohols to their corresponding carbonyl compounds by employing 2,2,6,6-tetramethylpiperidine-1-oxyl (TEMPO), $\mathrm{Co}\left(\mathrm{NO}_{3}\right)_{2}$ and dimethylglyoxime $\left(\mathrm{DH}_{2}\right)$ as a combined catalytic system [35]. We found that a considerable amount of acetals were generated if ethanol was used as the solvent. Additional tests revealed that acetal formation occurred efficiently in the presence of $\mathrm{Co}\left(\mathrm{NO}_{3}\right)_{2}$ and $\mathrm{DH}_{2}$. Taking the results from our previous study on alcohol oxidation [35], we proposed that the in situ generated bisdimethylglyoximatocobalt(II) $\left(\mathrm{Co}(\mathrm{DH})_{2}\right.$, cobaloxime) played the catalytic role in this acetalization. As far as we are aware, the catalytic properties of such Co complexes for acetalization and ketalization have not been studied yet. Moreover, it was notable that both the $\mathrm{DH}_{2}$ ligand and cobalt salt are simple, commonly used and inexpensive. Herein, the catalytic performance of cobaloxime was investigated by using various cobalt salts for acetalization and ketalization of different carbonyl compounds and polyhydric alcohols (Scheme 1).

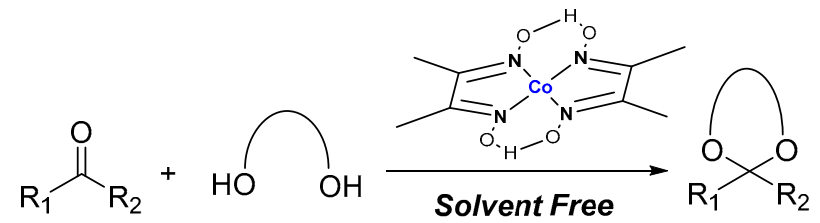

Scheme 1. Cobaloxime-catalyzed acetalization and ketalization.

\section{Results}

\subsection{The Catalytic Performances of $\mathrm{Co}\left(\mathrm{NO}_{3}\right)_{2}$ and $\mathrm{DH}_{2}$}

Due to their reversible features, acetalization and ketalization are often facilitated by removing water generated during the reaction processes. By using cyclohexanone $(12.0 \mathrm{mmol})$ and propane-1,2-diol (18.1 mmol) as the substrates, our initial test was carried out with $1 \mathrm{~mol} \% \mathrm{Co}\left(\mathrm{NO}_{3}\right)_{2}$ and $3 \mathrm{~mol} \% \mathrm{DH}_{2}$ in $20 \mathrm{~mL}$ benzene under refluxing for $1 \mathrm{~h}$. The ketalization of cyclohexanone was achieved in a conversion of $43.3 \%$ and a selectivity of $100 \%$ selectivity. When a Dean-Stark trap was implemented to remove water, the conversion rate increased to $59.5 \%$ for $1 \mathrm{~h}$, and $65.6 \%$ for $5 \mathrm{~h}$. This showed that prolongation of reaction time did not significantly increase the conversion rate. Then, the next tests were conducted in the absence of any solvent with a pressure of $5 \mathrm{KPa}$ (Table 1 ). After $1 \mathrm{~h}$ at room temperature, a conversion of $60.8 \%$ was achieved (entry 1 , Table 1 ), which was similar to the reaction result in the benzene solution with water being removed during the reaction process. Further investigation showed that the conversion occurred most effectively when the temperature was increased from room temperature to $70^{\circ} \mathrm{C}$. Nevertheless, when the temperature increased from $70{ }^{\circ} \mathrm{C}$ to $90{ }^{\circ} \mathrm{C}$, there was little change in conversion rate (entries $1-7$, Table 1 ). Therefore, $70{ }^{\circ} \mathrm{C}$ was the preferable temperature for the ketalization, wherein a $99.6 \%$ conversion was realized (entry 5, Table 1). The effect of the loading amount of the catalysts on efficacy of ketalization was also investigated (entries 5, 8 and 9). To our surprise, the conversion reached as high as $99.6 \%$ under the same conditions in the presence of $0.1 \mathrm{~mol} \% \mathrm{Co}\left(\mathrm{NO}_{3}\right)_{2}$ and $0.3 \mathrm{~mol} \% \mathrm{DH}_{2}$. In sharp contrast, almost no reaction was observed in the absence of either one of the two chemicals (entries 10 and 11), indicating that both of the components were indispensable. Besides, when equimolar propane-1,2-diol was used to react with cyclohexanone, the conversion still reached $90.3 \%$ (entry 12 ). 
Table 1. Ketalization of cyclohexanone with propane-1,2-diol catalyzed by $\mathrm{Co}\left(\mathrm{NO}_{3}\right)_{2}$ and $\mathrm{DH}_{2}{ }^{1}$.

\begin{tabular}{cccc}
\hline Entry & $\mathbf{C o}\left(\mathbf{N O}_{3}\right)_{\mathbf{2}}(\mathbf{m o l} \mathbf{\%})$ & $\mathbf{T}\left({ }^{\circ} \mathbf{C}\right)$ & Conversion $(\%){ }^{2}$ \\
\hline 1 & 1 & 25 & 60.8 \\
2 & 1 & 40 & 82.1 \\
3 & 1 & 50 & 90.8 \\
4 & 1 & 60 & 91.7 \\
5 & 1 & 70 & 99.8 \\
6 & 1 & 80 & 99.8 \\
7 & 1 & 90 & 99.3 \\
8 & 0.5 & 70 & 99.5 \\
9 & 0.1 & 70 & 99.6 \\
$10^{3}$ & 0.1 & 70 & 5.6 \\
11 & 0 & 70 & 1.5 \\
$12^{4}$ & 0.1 & 70 & 90.3 \\
\hline
\end{tabular}

${ }^{1}$ Reaction conditions: $51.3 \mathrm{mmol}$ cyclohexanone, $76.9 \mathrm{mmol}$ propane-1,2-diol, the molar rate of $\mathrm{Co}$ and $\mathrm{DH}_{2}$ is 1 to 3 in all case, $1 \mathrm{~h}, 5 \mathrm{KPa}$ pressure. ${ }^{2}$ The conversions and selectivities were based on Gas Chromatography (GC) with area normalization, and the selectivities of ketal were $100 \%$ in all cases. ${ }^{3}$ In the absence of $\mathrm{DH}_{2} \cdot{ }^{4} 51.3 \mathrm{mmol}$ propane-1,2-diol.

Figure 1 depicts the variations of conversion and turnover frequency (TOF) of the Co catalytic center during the reaction process. As can be seen, there is a remarkable increase in conversion in the early stage of reaction, and a subsequent slow growth. The deceleration in the conversion in the later period is due to the gradually decreasing concentration of reactants. However, it is notable that the TOF reached as high as $4188 \mathrm{~h}^{-1}$ at the ten-minute point, and $996 \mathrm{~h}^{-1}$ even at the one-hour point, from where the ketalization proceeded to near completeness ( $99.6 \%$ conversion). These results indicated that $\mathrm{Co} / \mathrm{DH}_{2}$ displays very highly catalytic activity for ketalization.

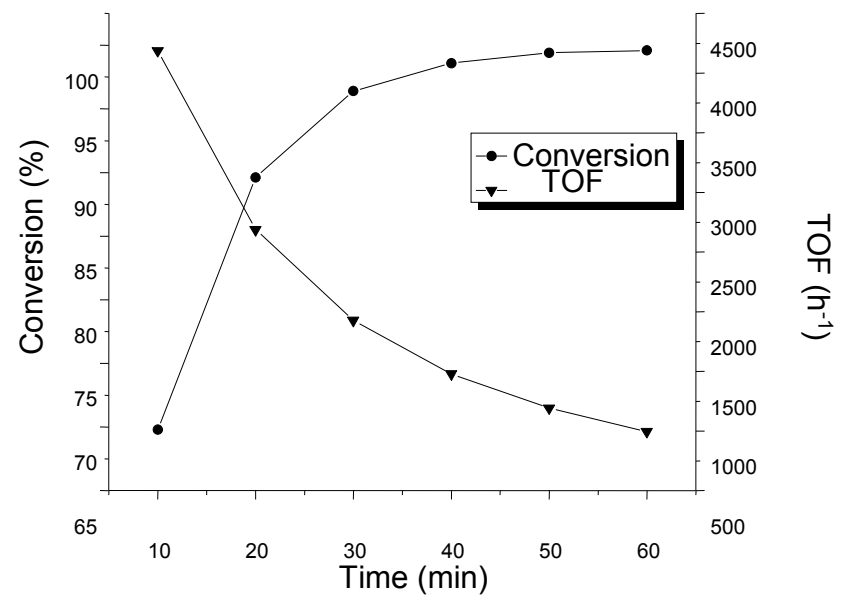

Figure 1. The time-varied conversions and turnover frequencies. Reaction conditions: $51.3 \mathrm{mmol}$ cyclohexanone, $76.9 \mathrm{mmol}$ propane-1,2-diol, $0.1 \mathrm{~mol} \% \mathrm{Co}\left(\mathrm{NO}_{3}\right)_{2}, 0.3 \mathrm{~mol} \% \mathrm{DH}_{2}, 5 \mathrm{KPa}$ pressure, $70{ }^{\circ} \mathrm{C}$.

\subsection{Studies on Various Cobalt Salts}

The screening of cobalt salts was performed by employing four common cobalt salts for the ketalization of cyclohexanone at optimal conditions (Table 2). As shown, $\mathrm{CoCl}_{2}$ displayed better catalytic activity $\left(95.3 \%\right.$ conversion, $953 \mathrm{~h}^{-1} \mathrm{TOF}$, entry 1 , Table 2$)$ than $\mathrm{Co}\left(\mathrm{NO}_{3}\right)_{2}(90.1 \%$ conversion, entry 2, Table 2). However, $\mathrm{CoSO}_{4}$ afforded a much lower conversion, and $\mathrm{Co}(\mathrm{OAc})_{2}$ failed to catalyze the ketalization (entry 4), implying that the anion of cobalt salt is one of the determinants affecting the catalytic activity. 
Table 2. Ketalization of cyclohexanone using different cobalt salts in the presence of $\mathrm{DH}_{2}{ }^{1}$.

\begin{tabular}{ccc}
\hline Entry & Cobalt Salt & Conversion (\%) \\
\hline 1 & $\mathrm{CoCl}_{2}$ & 95.3 \\
2 & $\mathrm{Co}\left(\mathrm{NO}_{3}\right)_{2}$ & 90.1 \\
3 & $\mathrm{CoSO}$ & 49.0 \\
4 & $\mathrm{Co}(\mathrm{OAc})_{2}$ & - \\
$5^{2}$ & $\mathrm{CoCl}$ & - \\
\hline
\end{tabular}

1 Reaction conditions: $0.1 \mathrm{~mol} \%$ Cobalt salt, $51.3 \mathrm{mmol}$ cyclohexanone, $51.3 \mathrm{mmol}$ propane-1,2-diol, $1 \mathrm{~h}$. Other reaction conditions were as described in Figure $1 .{ }^{2} 0.2 \mathrm{~mol} \% \mathrm{NaOAc}$ was added.

The generation of cobaloxime by $\mathrm{CoCl}_{2}$ and $\mathrm{DH}_{2}$ will release two equivalent $\mathrm{HCl}$ molecules. Under the condition of $5 \mathrm{KPa}$ pressure and $70{ }^{\circ} \mathrm{C}$, volatile $\mathrm{HCl}$ could easily escape from the reaction mixture. Therefore, the in situ formed cobaloxime has two unoccupied axial sites, which could serve as the catalytic sites (entry 1, Table 2). Also, $\mathrm{Co}\left(\mathrm{NO}_{3}\right)_{2} / \mathrm{DH}_{2}$ due to the $\mathrm{HNO}_{3}$ molecule could degrade to $\mathrm{NO}_{2}$ and escape. $\mathrm{H}_{2} \mathrm{SO}_{4}$ and $\mathrm{HOAc}$ molecules could hardly escape from the reaction system, so $\mathrm{CoSO}_{4} / \mathrm{DH}_{2}$ and $\mathrm{Co}(\mathrm{OAc})_{2} / \mathrm{DH}_{2}$ did not work well. Interestingly, since $\mathrm{H}_{2} \mathrm{SO}_{4}$ molecules remained in the reaction mixture and still coordinated with the Co center, the corresponding cobaloxime would have only one axial site left and thus produce moderate catalytic activity. For the same reason, the cobaloxime of $\mathrm{Co}(\mathrm{OAc})_{2} / \mathrm{DH}_{2}$ had no axial site and thus was inert to the ketalization. In addition, when $\mathrm{NaOAc}$ was added into the reaction system with $\mathrm{CoCl}_{2} / \mathrm{DH}_{2}$, no ketalization occurred (entry 5 , Table 2. To prove our theory, tris(dimethylglyoximato) cobalt(III), which has three ligands coordinated to one cobalt central and no unoccupied axial sites, was prepared [36] and used as the catalyst for the template reaction. Ketalization did not occur, which proved that such a hexacoodinate complex had no catalytic activity. From the above discussion, it could be implied that the axial sites of the cobalt center in planar tetracoordinate cobaloxime were assigned as a catalytic center for ketalization.

The effects of molar ratios of $\mathrm{DH}_{2}$ to cobalt salts on the catalytic performance are shown in Figure 2. As can be seen, for either $\mathrm{CoCl}_{2}$ or $\mathrm{Co}\left(\mathrm{NO}_{3}\right)_{2}$, when the ratios were below 2:1, the conversion increased fast along with the increase in the $\mathrm{DH}_{2}$ loading. Nevertheless, the conversions stayed at a very steady level when the ratios were equal to or were larger than 2:1. The results showed clearly that the optimal molar ratio of $\mathrm{DH}_{2}$ to cobalt salts was $2: 1$, and that the excess amount of $\mathrm{DH}_{2}$ did not enhance the catalyst performance. It was notable that this ratio coincided with the ratio of $\mathrm{DH}_{2}$ to Co in cobaloxime. Therefore, it is probable that cobaloxime formed in situ during the catalytic process, and played a key role as the catalyst in the ketalization.

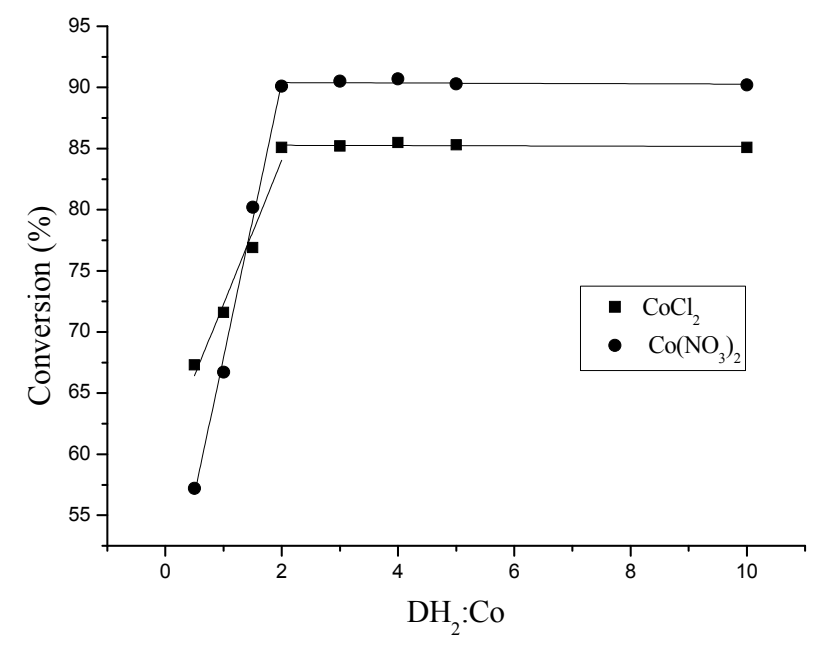

Figure 2. The conversions at different molar ratio of $\mathrm{DH}_{2}$ to $\mathrm{Co}$. Reaction conditions were as described in Table 2. For $\mathrm{CoCl}_{2}$ the reaction time was $0.5 \mathrm{~h}$, and for $\mathrm{Co}\left(\mathrm{NO}_{3}\right)_{2}$ the reaction time was $1 \mathrm{~h}$. 


\subsection{Various Ketalizations and Acetalizations}

To further investigate the scope of this catalytic reaction, acetalization and ketalization of various substrates were carried out with $\mathrm{CoCl}_{2} / \mathrm{DH}_{2}$ under the optimized conditions (Table 3). As shown, acetalization and ketalization of most carbonyl compounds with polyhydric alcohols could be catalyzed effectively by $\mathrm{CoCl}_{2} / \mathrm{DH}_{2}$. The reaction of cyclohexanone and ethane-1,2-diol also achieved an excellent conversion of $99.2 \%$ (entry 1, Table 3) which was quite similar to that of propane-1,2-diol. When benzaldehyde reacted with propane-1,2-diol or ethane-1,2-diol, nearly full conversions were reached within $3 \mathrm{~h}$, respectively (entries 2 and 3 ). However, the ketalization of acetophenone only gave a moderate yield (entries 4 and 5), and the ketalization of benzophenone did not occur (entry 6), even with increased catalyst loading and an extended reaction duration. These results can probably be explained as that the bulk substituents on the carbonyl hindered its effective coordination to the cobalt center.

Table 3. Ketalization (acetalization) of various ketones (aldehydes) catalyzed by $\mathrm{CoCl}_{2} / \mathrm{DH}_{2}{ }^{1}$.

\begin{tabular}{|c|c|c|c|c|c|c|}
\hline Entry & Carbonyl Compound & Alcohol & $\begin{array}{c}\mathrm{CoCl}_{2} \\
(\mathrm{~mol} \%)\end{array}$ & $\begin{array}{l}\text { Temperature } \\
\left({ }^{\circ} \mathrm{C}\right)\end{array}$ & $\begin{array}{l}\text { Time } \\
\text { (h) }\end{array}$ & Product/Yield (\%) \\
\hline 1 & cyclohexanone & ethane-1,2-diol & 0.1 & 70 & 1 & \\
\hline 2 & benzaldehyde & propane-1,2-diol & 0.1 & 70 & 3 & \\
\hline 3 & benzaldehyde & ethane-1,2-diol & 0.1 & 70 & 3 & \\
\hline 4 & acetophenone & propane-1,2-diol & 1 & 90 & 9 & \\
\hline 5 & acetophenone & ethane-1,2-diol & 1 & 90 & 7 & \\
\hline 6 & benzophenone & propane-1,2-diol & 1 & 90 & & - \\
\hline 7 & ethyl acetoacetate & ethane-1,2-diol & 1 & 70 & 8 & \\
\hline 8 & ethyl acetoacetate & propane-1,2-diol & 1 & 70 & 8 & \\
\hline 9 & cyclohexanone & glycerol & 0.1 & 70 & 4 & \\
\hline 10 & benzaldehyde & glycerol & 0.1 & 70 & 6 & \\
\hline 11 & ethyl acetoacetate & glycerol & 1 & 70 & 8 & \\
\hline 12 & acetophenone & glycerol & 1 & 90 & 12 & \\
\hline
\end{tabular}


Table 3. Cont.

\begin{tabular}{|c|c|c|c|c|c|c|}
\hline Entry & Carbonyl Compound & Alcohol & $\begin{array}{c}\mathrm{CoCl}_{2} \\
(\mathrm{~mol} \%)\end{array}$ & $\begin{array}{l}\text { Temperature } \\
\left({ }^{\circ} \mathrm{C}\right)\end{array}$ & $\begin{array}{l}\text { Time } \\
\text { (h) }\end{array}$ & Product/Yield (\%) \\
\hline 13 & cyclohexanone & butane-1,4-diol & 0.1 & 80 & 7 & \\
\hline 14 & benzaldehyde & butane-1,4-diol & 0.1 & 80 & 7 & 869 \\
\hline 15 & acetophenone & butane-1,4-diol & 1 & 100 & 10 & \\
\hline
\end{tabular}

The cyclic ketals of ethyl acetoacetate are often used as flavor material [2]. Encouragingly, in $70{ }^{\circ} \mathrm{C}$ for $8 \mathrm{~h}$, ketalization of ethyl acetoacetate with ethane-1,2-diol and propane-1,2-diol achieved a 95.9\% yield of ethyl 2-(2,4-dimethyl-1,3-dioxolan-2-yl)acetate (Fructone, entry 7) and a 96.7\% yield of ethyl 2-(2-methyl-1,3-dioxolan-2-yl)acetate (Fructone-B, entry 8), respectively, which could have significant benefits for industry.

Glycerolacetals/ketals have wide applications as fragrances, surfactants, food and beverage additives, fine intermediates, in lacquer industries and as ignition accelerators and anti-knock additives in combustion engines [16]. Catalyzed by $\mathrm{CoCl}_{2} / \mathrm{DH}_{2}$, ketalization of glycerol with cyclohexanone, benzaldehyde and ethyl acetoacetate reached approximately full conversions (entries 9-11), whereas, acetophenone gave a moderate yield. Among them, the formation of five-membered cyclic ketals is preferable.

It was interesting to find that seven-membered cyclic ketals could be easily generated (entries 13-15). Although the reaction of acetophenone with butane-1,4-diol took place slowly, the ketalization of butane-1,4-diol with cyclohexanone, and benzaldehyde achieved moderate to excellent yields of the corresponding seven-membered cyclic ketals. This provides a potential method for the preparation of large cyclic ketals.

\subsection{The Suggested Catalytic Mechanism}

Notably, a small quantity of 1,3-diphenylbut-2-en-1-one was generated in the reaction of acetophenone and butane-1,4-diol (see the Supplementary Materials), which was the product of self-aldol condensation of acetophenone. This means that the more electrophilic species of carbonyl will form in the reaction.

According to the above experimental results, the general mechanism of this new catalytic acetalization and ketalizationis proposed in Figure 3. In the reactions with $\mathrm{CoCl}_{2} / \mathrm{DH}_{2}$ and/or $\mathrm{Co}\left(\mathrm{NO}_{3}\right)_{2} / \mathrm{DH}_{2}$ under $5 \mathrm{KPa}$ pressure and $70{ }^{\circ} \mathrm{C}$, the planar tetracoordinate cobaloxime was formed in situ with two unoccupied axial sites. The carbonyl group of aldehyde or ketone coordinates to the cobalt center of cobaloxime in end-on type, which results in the $C$ of carbonyl becoming more electrophilic due to electron transfer of carbonyl to the cobalt center. Then, such active carbonyl is attacked by one hydroxyl of polyhydric alcohol to form a protonated alkyloxyalkylolate on the cobalt center. Afterwards, an intramolecular nucleophilic substitution takes place between oxygen anion and $\alpha-C$ of the second hydroxyl of alkyloxyalkylolate, leading to the recovery of cobaloxime and the generation of the acetal/ketal product. 


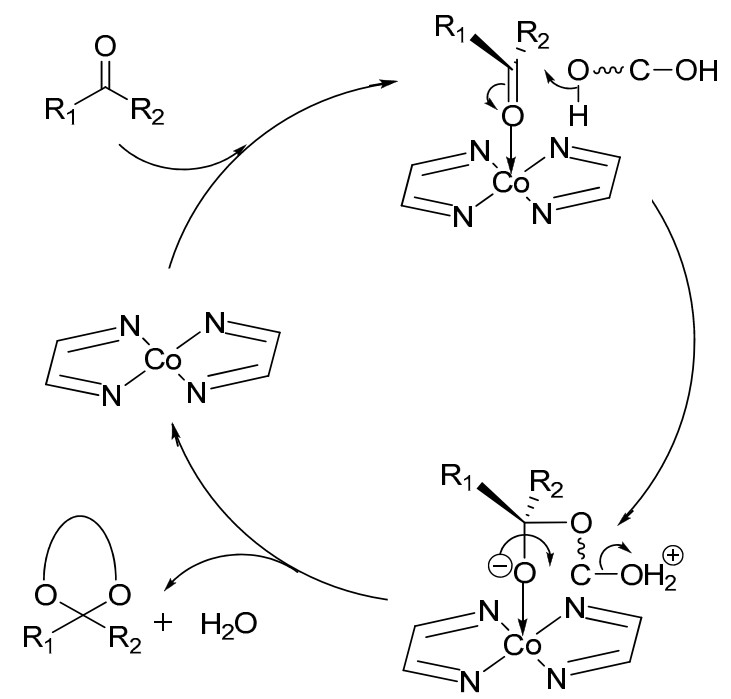

Figure 3. The suggested catalytic mechanism.

\section{Conclusions}

In summary, a highly efficient catalytic system consisting of $\mathrm{CoCl}_{2}$ (or $\left.\mathrm{Co}\left(\mathrm{NO}_{3}\right)_{2}\right)$ and $\mathrm{DH}_{2}$ was developed to perform the acetalization and ketalization of various carbonyl compounds with polyhydric alcohols. The corresponding cyclic acetals and/or ketals were formed under solvent-free mild conditions and a $5 \mathrm{KPa}$ pressure. Wherein, the simple and non-noble metal catalyst, $\mathrm{CoCl}_{2} / \mathrm{DH}_{2}$, displayed excellent catalytic performance, where TOF reached as high as $953 \mathrm{~h}^{-1}$. During the catalytic process, the in situ generated planar tetracoordinate cobaloxime played a key role. The general mechanism was suggested, which includes a coordination-activation of the carbonyl, an intermolecular electrophilic attack to hydroxyl and an intramolecular nucleophilic substitution. Conclusively, our methodology provides a noncorrosive and simple way to synthesize cyclic acetals and ketals. Moreover, the availability of inexpensive $\mathrm{CoCl}_{2}$ and $\mathrm{DH}_{2}$ makes the process an attractive method of acetalization and ketalization for industrial manufacturing.

\section{Materials and Methods}

All starting materials were purchased from commercial sources and used without further treatment. Gas chromatography measurements (Agilent Technologies, Inc., Santa Clara, CA, USA) were conducted using an Agilent Technologies 6890N Network GC system with a flame ionization detector and an INNOWAX capillary column $(30 \mathrm{~m} \times 0.53 \mathrm{~mm} \times 1 \mu \mathrm{m})$. Agilent chemstation software (Agilent Technologies 6890N Network, Agilent Technologies, Inc., Santa Clara, CA, USA) was used for spectra acquisition and processing. The conversions of substrates were determined by GC area normalization. A Bruker GC-MS spectrometer (Ruker Daltonics Inc., Fremont, CA, USA) was used for determination of the acetal and ketal products.

General Procedure: All the catalytic reactions were performed in a $50 \mathrm{~mL}$ three-necked round-bottom flask equipped with a magnetic stirrer. Typically, a mixture of cyclohexanone ( $51.3 \mathrm{mmol})$, propane-1,2-diol (51.3 mmol), $\mathrm{CoCl}_{2}(0.1 \mathrm{~mol} \%)$ and $\mathrm{DH}_{2}(0.2 \mathrm{~mol} \%)$ were charged into the flask and heated to $70{ }^{\circ} \mathrm{C}$ along with stirring. Afterwards, the system pressure of $5 \mathrm{KPa}$ was obtained by a vacuum pump and maintained during the period of reaction. The progress of the reaction was monitored by GC analysis of small aliquots drawn from the reaction mixture. The reaction was stopped when GC showed that the reaction was completed. After being cooled to room temperature, the reaction mixture was transferred into a separating funnel. $15 \mathrm{~mL} \mathrm{CH}_{2} \mathrm{Cl}_{2}$ was used to wash the reaction flask and poured into the funnel. The combined mixture was washed with saturated sodium 
carbonate solution $(4 \times 5 \mathrm{~mL})$ and dried by anhydrous $\mathrm{Na}_{2} \mathrm{SO}_{4}$. Then, the mixture was distilled under vacuum to give the acetal (or ketal) product.

Supplementary Materials: The following are available online at www.mdpi.com/2073-4344/8/2/48/s1. Figure S1: GC-MS spectrum of the reaction of cyclohexanone and propane-1,2-diol, Figure S2: GC-MS spectrum of the reaction of cyclohexanone and ethane-1,2-diol, Figure S3: GC-MS spectrum of the reaction of benzaldehyde and propane-1,2-diol, Figure S4: GC-MS spectrum of the reaction of benzaldehyde and ethane-1,2-diol, Figure S5: GC-MS spectrum of the reaction of acetophenone and propane-1,2-diol, Figure S6: GC-MS spectrum of the reaction of acetophenone and ethane-1,2-diol, Figure S7: GC-MS spectrum of the reaction of ethyl acetoacetate and ethane-1,2-diol, Figure S8: GC-MS spectrum of the reaction of ethyl acetoacetate and propane-1,2-diol, Figure S9: GC-MS spectrum of the reaction of cyclohexanone and glycerol, Figure S10: GC-MS spectrum of the reaction of benzaldehyde and glycerol, Figure S11: $(a, b)$ GC-MS spectrum of the reaction of ethyl acetoacetate and glycerol, Figure S12: GC-MS spectrum of the reaction of acetophenone and glycerol, Figure S13: GC-MS spectrum of the reaction of cyclohexanone and butane-1,4-diol, Figure S14: GC-MS spectrum of the reaction of benzaldehyde and butane-1,4-diol, Figure S15: GC-MS spectrum of the reaction of acetophenone and butane-1,4-diol, Figure S16: ${ }^{1} \mathrm{H}-\mathrm{NMR}$ spectrum of the reaction product of cyclohexanone and propane-1,2-diol, Figure S17: ${ }^{1} \mathrm{H}-\mathrm{NMR}$ spectrum of the reaction product of benzaldehyde and propane-1,2-diol, Figure S18: ${ }^{1} \mathrm{H}-\mathrm{NMR}$ spectrum of the main product of reaction of cyclohexanone and glycerol.

Acknowledgments: This work was supported by National Natural Science Foundation of China (No.21502174).

Author Contributions: Bingxin Yuan and Guanyu Yang conceived and designed the experiments; Yang Zong, Liting Yang, Shanyu Tang and Longjia Li performed the experiments; Bingxin Yuan and Guanyu Yang analyzed the data; Wanjie Wang and Guanyu Yang contributed reagents and analysis tools; Bingxin Yuan wrote the paper.

Conflicts of Interest: The authors declare no conflict of interest.

\section{References}

1. Greene, T.W.; Wuts, P.G.M. Greene's Protective Groups in Organic Synthesis, 4th ed.; John Wiley and Sons: New York, NY, USA, 2007.

2. Bauer, K.; Garbe, D.; Surburg, H. Common Fragrances and Flavors Materials, 4th ed.; Wiley: New York, NY, USA, 2001.

3. Dauben, W.G.; Gerdes, J.M.; Look, G.C. Organic Reactions at High Pressure. Conversion of Cyclic Alkanones and Enones to 1,3-Dioxolane. J. Org. Chem. 1986, 51, 4964-4970. [CrossRef]

4. Thurkauf, A.; Jacobson, A.E.; Rice, K.C. An improved procedure for the preparation of acetals from diaryl ketones. Synthesis 1988, 3, 233-234. [CrossRef]

5. Leonard, N.M.; Oswald, M.C.; Freiberg, D.A.; Nattier, B.A.; Smith, R.C.; Mohan, R.S. A simple and versatile method for the synthesis of acetals from aldehydes and ketones using bismuth triflate. J. Org. Chem. 2002, 67, 5202-5207. [CrossRef] [PubMed]

6. Wu, S.S.; Dai, W.L.; Yin, S.F.; Li, W.S.; Au, C.T. Bismuth subnitrate as an efficient heterogeneous catalyst for acetalization and ketalization of carbonyl compounds with diols. Catal. Lett. 2008, 124, 127-132. [CrossRef]

7. Kumar, R.; Chakraborti, A.K. Copper(II) tetrafluoroborate as a novel and highly efficient catalyst for acetal formation. Tetrahedron Lett. 2005, 46, 8319-8323. [CrossRef]

8. Cataldo, M.; Nieddu, E.; Gavagnin, R.; Pinna, F.; Strukul, G. Hydroxy complexes of palladium(II) and platinum(II) as catalysts for the acetalization of aldehydes and ketones. J. Mol. Catal. A Chem. 1999, 142, 305-316. [CrossRef]

9. Smith, B.M.; Graham, A.E. Indium triflate mediated acetalization of aldehydes and ketones. Tetrahedron Lett. 2006, 47, 9317-9319. [CrossRef]

10. Jermy, B.R.; Pandurangan, A. Efficient synthesis of diacetal of pentaerythritol under microwave irradiation using heteropoly acid $\mathrm{H}_{3} \mathrm{PW}_{12} \mathrm{O}_{40}$. Catal. Commun. 2006, 7, 921-925. [CrossRef]

11. Jermy, B.R.; Pandurangan, A. $\mathrm{H}_{3} \mathrm{PW}_{12} \mathrm{O}_{40}$ supported on MCM-41 molecular sieves: An effective catalyst for acetal formation. Appl. Catal. A Gen. 2005, 295, 185-192. [CrossRef]

12. Patel, S.M.; Chudasama, U.V.; Ganeshpure, P.A. Ketalization of ketones with diols catalyzed by metal(IV) phosphates as solid acid catalysts. J. Mol. Catal. A Chem. 2003, 194, 267-271. [CrossRef]

13. Ajaikumar, S.; Pandurangan, A. Reaction of benzaldehyde with various aliphatic glycols in the presence of hydrophobic Al-MCM-41: A convenient synthesis of cyclic acetals. J. Mol. Catal. A Chem. 2008, 290, 35-43. [CrossRef] 
14. Dhakshinamoorthy, A.; Alvaro, M.; Garcia, H. Metal organic frameworks as solid acid catalysts for acetalization of aldehydes with methanol. Adv. Synth. Catal. 2010, 352, 3022-3030. [CrossRef]

15. Karimi, B.; Ghoreishi-Nezhad, M. Highly chemoselective acetalization of carbonyl compounds catalyzed by a novel recyclable ammonium triflate-functionalized silica. J. Mol. Catal. A Chem. 2007, 277, 262-265. [CrossRef]

16. Umbarkar, S.B.; Kotbagi, T.V.; Biradar, A.V.; Pasricha, R.; Chanale, J.; Dongare, M.K.; Mamede, A.S.; Lancelot, C.; Payen, E. Acetalization of glycerol using mesoporous $\mathrm{MoO}_{3} / \mathrm{SiO}_{2}$ solid acid catalyst. J. Mol. Catal. A Chem. 2009, 310, 150-158. [CrossRef]

17. Venkatachalam, K.; Palanichamy, M.; Murugesan, V. Acetalization of heptanal over Al-SBA-1 molecular sieve. Catal. Commun. 2010, 12, 299-303. [CrossRef]

18. Xu, C.; Zheng, L.; Deng, D.; Liu, J.; Liu, S. Effect of activation temperature on the surface copper particles and catalytic properties of $\mathrm{Cu}-\mathrm{Ni}-\mathrm{Mg}-\mathrm{Al}$ oxides from hydrotalcite-like precursors. Catal. Commun. 2011, 12, 996-999. [CrossRef]

19. Yamada, Y.; Qiao, K.; Bao, Q.; Tomida, D.; Nagao, D.; Konno, M.; Yokoyama, C. Preparation and catalytic use of silica-polymer core-shell microspheres with imidazolium-styrene copolymer shells. Catal. Commun. 2009, 11, 227-231. [CrossRef]

20. Yuan, C.; Zhang, F.; Wang, J.; Ren, X. 12-Phosphotungstic acid and its CS salt supported on various porous carriers as catalysts for the synthesis of fructone. Catal. Commun. 2005, 6, 721-724. [CrossRef]

21. Miao, J.; Wan, H.; Shao, Y.; Guan, G.; Xu, B. Acetalization of carbonyl compounds catalyzed acidic ionic liquid immobilized on silica gel. J. Mol. Catal. A Chem. 2011, 348, 77-82. [CrossRef]

22. Wang, Y.; Gong, X.; Wang, Z.; Dai, L. $\mathrm{SO}_{3} \mathrm{H}$-functionalized ionic liquids as efficient and recyclable catalysts for the synthesis of pentaerythritol diacetals and diketals. J. Mol. Catal. A Chem. 2010, 322, 7-16. [CrossRef]

23. Liang, X.; Qi, C. Synthesis of a novel ionic liquid with both lewis and brønsted acid sites and its catalytic activities. Catal. Commun. 2011, 12, 808-812. [CrossRef]

24. Sugimura, R.; Qiao, K.; Tomida, D.; Yokoyama, C. Immobilization of acidic ionic liquids by copolymerization with styrene and their catalytic use for acetal formation. Catal. Commun. 2007, 8, 770-772. [CrossRef]

25. Karimi, B.; Ebrahimian, G.R.; Seradj, H. Efficient and chemoselective conversion of carbonyl compounds to 1,3-dioxanes catalyzed with $N$-bromosuccinimide under almost neutral reaction conditions. Org. Lett. 1999, 1, 1737-1739. [CrossRef]

26. Huo, C.; Chan, T.H. Carbon tetrabromide/sodium triphenylphosphine-m-sulfonate (TPPMS) as an efficient and easily recoverable catalyst for acetalization and tetrahydropyranylation reactions. Adv. Synth. Catal. 2009, 351, 1933-1938. [CrossRef]

27. Ott, J.; Ramos Tombo, G.M.; Schmid, B.; Venanzi, L.M.; Wang, G.; Ward, T.R. A versatile rhodium catalyst for acetalization reactions under mild conditions. Tetrahedron Lett. 1989, 30, 6151-6154. [CrossRef]

28. Hoffman, R.V. The $\mathrm{Rh}_{2}(\mathrm{CO})_{4} \mathrm{Cl}_{2}$ catalyzed acetalization of crotonaldehyde. Tetrahedron Lett. 1974, 15, 2415-2416. [CrossRef]

29. Zhu, Z.; Espenson, J.H. Organometallic catalysis: Formation of 1,3-dioxolanes and their analogs catalyzed by methylrhenium trioxide (MTO). Organometallics 1997, 16, 3658-3663. [CrossRef]

30. Ranu, B.C.; Jana, R.; Samanta, S. A simple, efficient and general procedure for acetalization of carbonyl compounds and deprotection of acetals under the catalysis of indium(III) chloride. Adv. Synth. Catal. 2004, 346, 446-450. [CrossRef]

31. Priyaa, S.; Selvakannana, P.R.; Chary, K.; Kantamc, M.; Bhargava, S. Solvent-free microwave-assisted synthesis of solketal from glycerol using transition metal ions promoted mordenite solid acid catalysts. Mol. Catal. 2017, 434, 184-193. [CrossRef]

32. Eshghi, H.; Rahimizadeh, M.; Saberi, S. Fe $\left(\mathrm{HSO}_{4}\right)_{3}$ as an inexpensive, eco-friendly, heterogeneous and reusable catalyst for acetal/ketal formation and their facile regeneration. Catal. Commun. 2008, 9, 2460-2466. [CrossRef]

33. Ji, S.; Wu, L. Acetalization of carbonyl compounds catalyzed by polymer-bound metal complexes. J. Mol. Catal. A 2003, 202, 41-46. [CrossRef]

34. Velusamy, S.; Punniyamurthy, T. Cobalt(II)-catalyzed chemoselective synthesis of acetals from aldehydes. Tetrahedron Lett. 2004, 45, 4917-4920. [CrossRef] 
35. Jing, Y.; Jiang, J.; Yan, B.; Lu, S.; Jiao, J.; Xue, H.; Yang, G.; Zheng, G. Activation of dioxygen by cobaloxime and nitric oxide for efficient tempo-catalyzed oxidation of alcohols. Adv. Synth. Catal. 2011, 353, 1146-1152. [CrossRef]

36. Nakahara, A.; Tsuchida, R. Synthesis of the tris-(dimethylglyoximo)-cobaltate(III). J. Am. Chem. Soc. 1954, 76, 3103. [CrossRef] 